\title{
Cost-Optimized Cold Climate Heat Pump Development and Field Test
}

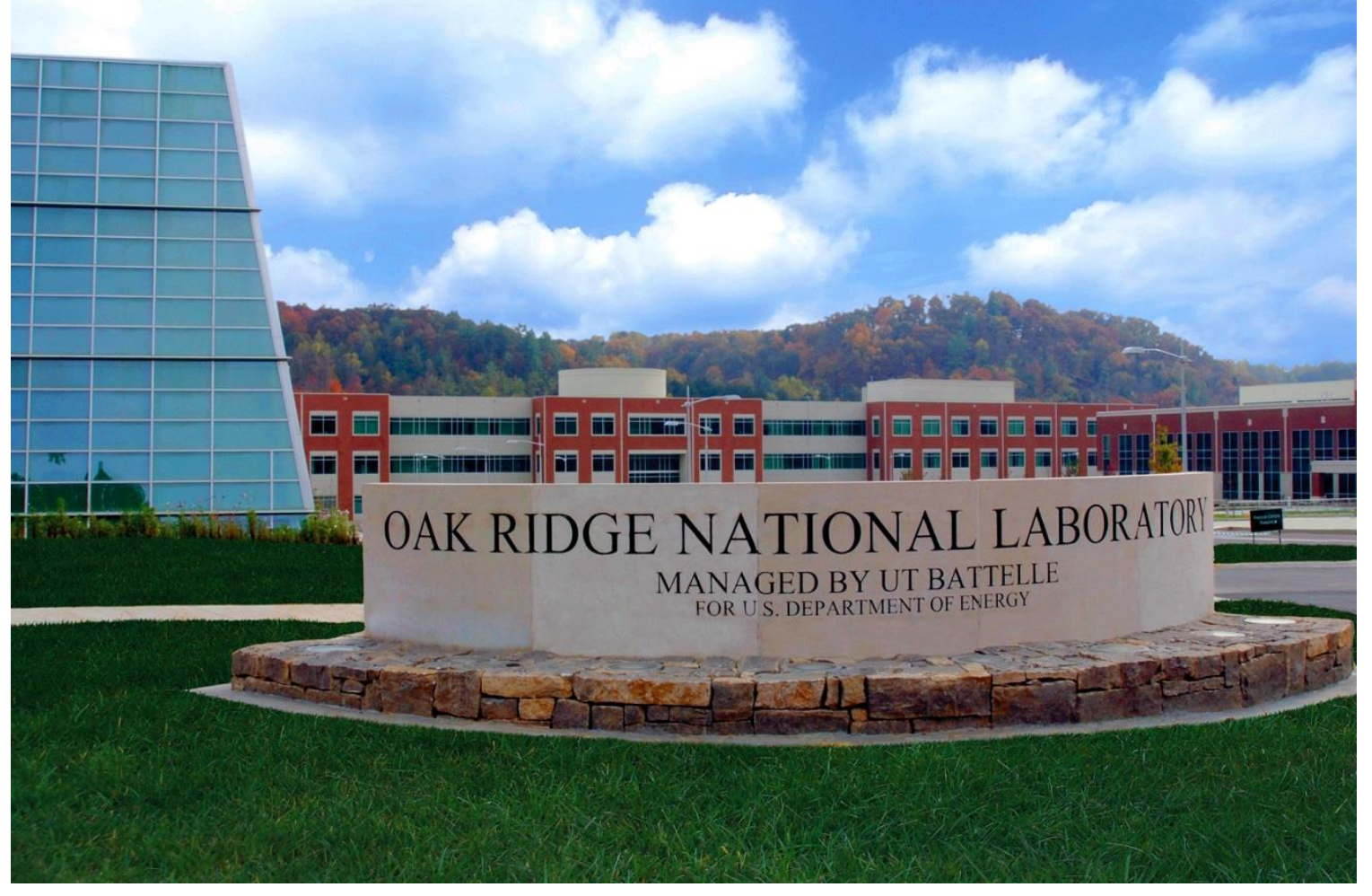

Jeff Munk

Bo Shen

Tony Gehl

August 2021 


\title{
DOCUMENT AVAILABILITY
}

Reports produced after January 1, 1996, are generally available free via US Department of Energy (DOE) SciTech Connect.

Website www.osti.gov

Reports produced before January 1, 1996, may be purchased by members of the public from the following source:

\author{
National Technical Information Service \\ 5285 Port Royal Road \\ Springfield, VA 22161 \\ Telephone 703-605-6000 (1-800-553-6847) \\ TDD 703-487-4639 \\ Fax 703-605-6900 \\ E-mail info@ntis.gov \\ Website http://classic.ntis.gov/
}

Reports are available to DOE employees, DOE contractors, Energy Technology Data Exchange representatives, and International Nuclear Information System representatives from the following source:

Office of Scientific and Technical Information

PO Box 62

Oak Ridge, TN 37831

Telephone 865-576-8401

Fax 865-576-5728

E-mail reports@osti.gov

Website http://www.osti.gov/

This report was prepared as an account of work sponsored by an agency of the United States Government. Neither the United States Government nor any agency thereof, nor any of their employees, makes any warranty, express or implied, or assumes any legal liability or responsibility for the accuracy, completeness, or usefulness of any information, apparatus, product, or process disclosed, or represents that its use would not infringe privately owned rights. Reference herein to any specific commercial product, process, or service by trade name, trademark, manufacturer, or otherwise, does not necessarily constitute or imply its endorsement, recommendation, or favoring by the United States Government or any agency thereof. The views and opinions of authors expressed herein do not necessarily state or reflect those of the United States Government or any agency thereof. 
Buildings and Transportation Science Division

\title{
COST-OPTIMIZED COLD CLIMATE HEAT PUMP DEVELOPMENT AND FIELD TEST
}

\author{
Jeff Munk \\ Bo Shen \\ Tony Gehl
}

August 2021

Prepared by

OAK RIDGE NATIONAL LABORATORY

Oak Ridge, TN 37831-6283

managed by

UT-BATTELLE LLC

for the

US DEPARTMENT OF ENERGY

under contract DE-AC05-00OR22725 



\section{CONTENTS}

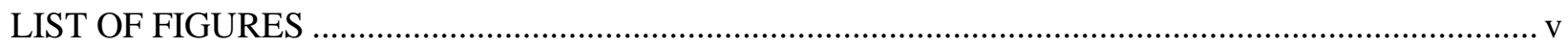

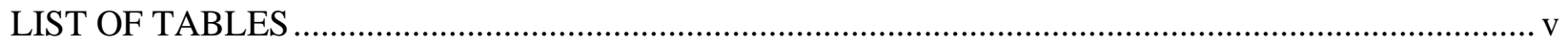

ACKNOWLEDGEMENTS .................................................................................................. vii

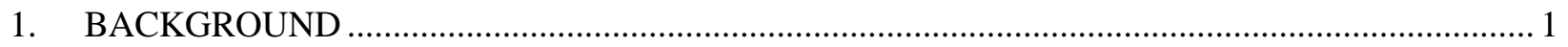

1.1 PREVIOUS OAK RIDGE NATIONAL LABORATORY CCHP DEVELOPMENT ............ 2

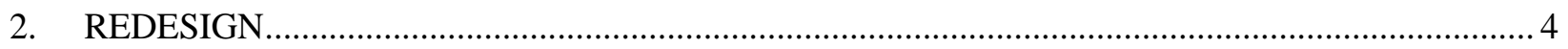

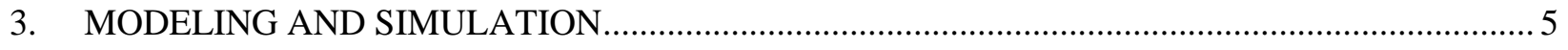

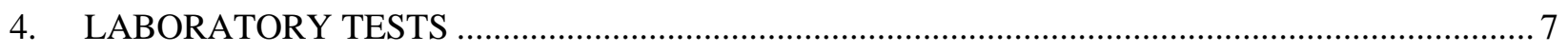

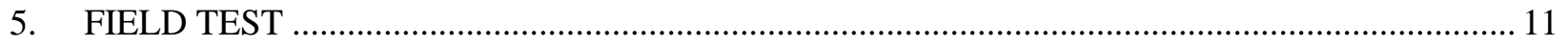

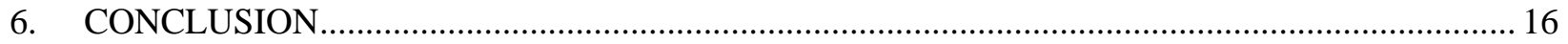

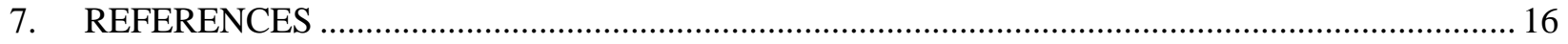





\section{LIST OF FIGURES}

Figure 1. Building heating load in Region V (DHRmin) compared with the heating capacity of a typical ASHP with 7.5 HSPF and a target CCHP with an equivalent nominal heating capacity at $47^{\circ} \mathrm{F}\left(8.7^{\circ} \mathrm{C}\right)$.

Figure 2. CCHP prototype using tandem, single-speed compressors and an EXV for discharge pressure control in the heating mode.

Figure 3. Diagram of speed controller and two-stage heat pump configuration used to achieve three stages of operation.

Figure 4. Compressor, speed controller, reversing valve, and accumulator on a pallet next to the outdoor unit heat exchanger as installed in the outdoor environmental chamber.

Figure 5. Indoor unit installed in the indoor environmental chamber.....

Figure 6. Laboratory-measured capacity of the prototype system along with performance targets if the system were rated as a 3.5-ton nominal cooling unit and 2.5-ton nominal cooling unit.

Figure 7. Laboratory-measured efficiency of the prototype system along with efficiency targets.

Figure 8. Compressor crate prior to shipment to the field test site ..................................................... 12

Figure 9. Mapping of two-stage thermostat calls for heating and cooling to compressor staging.............. 13

Figure 10. Average measured capacity of the field-test unit for hours with more than 5 min of runtime in the indicated stage compared with the measured laboratory data.

Figure 11. Average measured COP of the field-test unit for hours with more than $5 \mathrm{~min}$ of runtime in the indicated stage compared with the measured laboratory data.

Figure 12. Plot of the percentage of runtime in defrost mode for $5^{\circ} \mathrm{F}$ outdoor temperature bins $\left(2.7^{\circ} \mathrm{C}\right.$ bins) with labels showing minutes of runtime in defrost mode.

\section{LIST OF TABLES}

Table 1. Predicted heating performance of the improved CCHP. 6

Table 2. Predicted cooling performance of the improved CCHP. 7

Table 3. Estimated seasonal efficiencies based on laboratory test data. 



\section{ACKNOWLEDGEMENTS}

Funding for this research was provided by the US Department of Energy, Office of Energy Efficiency and Renewable Energy. The authors would like to thank Marc LaFrance and Dale Hoffmeyer, technology managers for the Residential Building Integration program, for their support of this work. The authors would also like to thank their industry partners at Emerson Climate Technologies, Brian Knapke, Brian Butler, and Dan Knoth, as well as Jie Chen of Nortek LLC, for assisting with the development of the cold climate heat pump system and donating components for building the prototypes. Thanks also go to Robbin Garber-Slaght of the National Renewable Energy Laboratory Cold Climate Housing Research Center in Fairbanks, Alaska for managing the installation and aiding with troubleshooting of the prototype system. 



\section{BACKGROUND}

Cold climate heat pumps (CCHPs) expand the heat pump market to climates where heating demand is dominant. They can achieve more than $70 \%$ energy savings compared with electric resistance heating and operate at lower cost than using tank-stored propane to fuel a furnace. A high-efficiency heat pump with a heating seasonal performance factor (HSPF) — as defined by the Air-Conditioning, Heating, and Refrigeration Institute (AHRI 2008) - greater than 10.0 would be more efficient than gas heating in terms of source energy.

However, developing a cost-effective CCHP involves some challenges. A typical single-speed, air-source heat pump (ASHP) with an HSPF of 7.7 Btu/Wh, as shown in Figure 1, does not work well under cold outdoor temperature conditions typical of cold climate locations for four major reasons:

1. Discharge temperature is too high-The low suction pressure and high compression pressure ratio at low ambient temperatures causes high compressor discharge temperatures in excess of the maximum limit for many of the compressors on the market. Furthermore, system charge of a heat pump is usually optimized in the cooling mode, which leads to overcharge conditions in the heating mode, further increasing the discharge temperature.

2. Heating capacity is insufficient if sized to meet the building design cooling load - Heating capacity of a single-speed heat pump decreases with ambient temperature. As illustrated in Figure 1, the heating capacity at $-13^{\circ} \mathrm{F}\left(-25^{\circ} \mathrm{C}\right)$ typically decreases to $20 \%-40 \%$ of the rated heating capacity at $47^{\circ} \mathrm{F}\left(8.3^{\circ} \mathrm{C}\right)$ ( equivalent to the rated cooling capacity at $\left.95^{\circ} \mathrm{F}\left[35^{\circ} \mathrm{C}\right]\right)$. Therefore, a single-speed heat pump, typically sized to match the building design cooling load, cannot provide adequate heating capacity to match the building heating load at low ambient temperatures. The capacity deficit is filled by inefficient resistance heat, thus lowering the system efficiency and significantly increasing power demand.

3. Cyclic loss is significant if sized to meet the building design heating load-If a single-speed heat pump is sized to meet the heating load, it will be significantly oversized relative to the cooling load in many cold climates. This will cause excessive on/off cyclic loss during the cooling and heating operations at moderately low ambient temperatures. Thus, capacity modulation capability (e.g., using a variable-speed or multi-stage compressor) is necessary for a CCHP, which uses its full capacity to meet the peak heating load and partial capacity to meet the cooling and part-load heating loads.

4. Coefficient of performance (COP) is low-Heating COP degrades significantly at low ambient temperatures owing to the large temperature difference between the heat source and sink.

A target CCHP should be sized to meet the building design heating load while minimizing the cyclic loss for the cooling and heating operations at moderate ambient temperatures. 


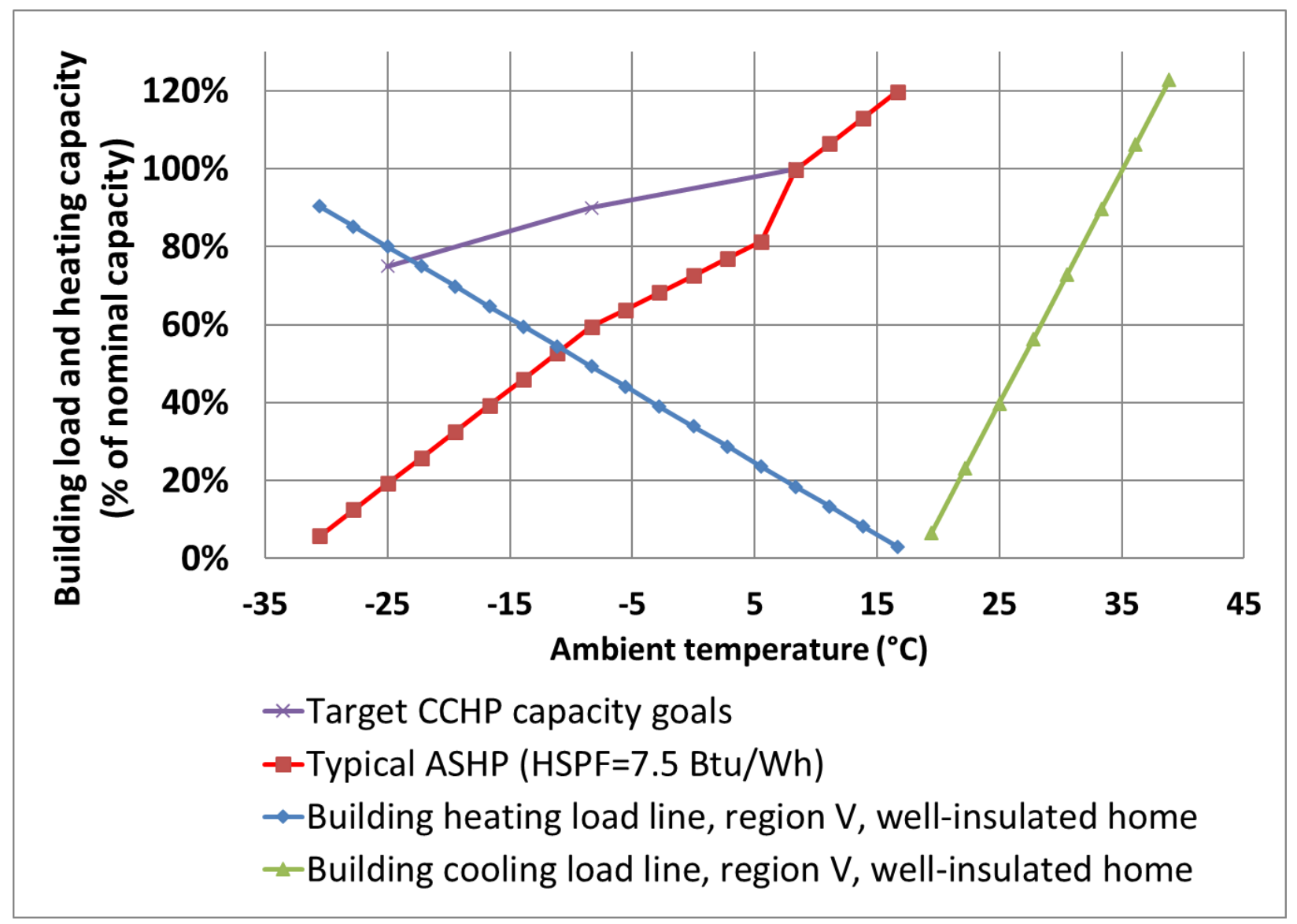

Figure 1. Building heating load in Region V (DHRmin) compared with the heating capacity of a typical ASHP with 7.5 Btu/Wh HSPF and a target $\mathrm{CCHP}$ with an equivalent nominal heating capacity at $47^{\circ} \mathrm{F}\left(8.7^{\circ} \mathrm{C}\right)$.

\subsection{PREVIOUS OAK RIDGE NATIONAL LABORATORY CCHP DEVELOPMENT}

For the CCHP development, cost-effective solutions should be identified to address the issues identified in Section 1. From 2010 to 2015, the US Department of Energy's (DOE's) Oak Ridge National Laboratory (ORNL) successfully developed and prototyped a CCHP design that used two identical scroll compressors in parallel (tandem). The system configuration is shown in Figure 2. The six major design considerations are summarized:

1. Most CCHPs on the market use premium variable-speed compressors and inverters. To take full advantage of a variable-speed heat pump's ability to modulate capacity, proprietary controls and thermostats from the manufacturer are required, further increasing the cost. To develop more costeffective CCHPs, the design used two single-stage compressors, which eliminate the need for an inverter and reduce the cost of controls. The two-stage CCHP would directly work with commercially available two-stage thermostats.

2. Two equally sized, single-speed compressors were obtained from Emerson Commercial \& Residential Solutions. These compressors featured special heating application design features, which allowed them to operate at higher discharge temperatures than most typical compressors (up to $280^{\circ} \mathrm{F}$ $\left[137.8^{\circ} \mathrm{C}\right]$ compared with $\left.230^{\circ} \mathrm{F}\left[110^{\circ} \mathrm{C}\right]\right)$. This capability enabled the CCHP prototype to work at extremely low ambient temperatures. 
3. The CCHP prototype operated a single compressor to meet the building cooling load. A single compressor also satisfied the heating load at mild ambient temperatures, but both compressors were necessary at low ambient temperatures. Two-stage heat pumps currently on the market use a single two-stage compressor with a displacement volume split ratio (ratio of displacement volume in high stage to the displacement volume in low stage) of 100\%:67\%. In comparison, the tandem compressors have a displacement volume split ratio of 100\%:50\%, which provides a larger overcapacity potential when the heat pump nominal capacity is established for the low-capacity (i.e., one compressor) level. This larger over-capacity potential allowed the CCHP prototype to reach $>75 \%$ capacity at $-13^{\circ} \mathrm{F}\left(-25^{\circ} \mathrm{C}\right)$.

4. The CCHP prototype was sized to match a 3-ton building cooling load using a single compressor. The system used heat exchangers typical of a 4.5-ton heat pump. When running a single compressor in the cooling mode and at moderate temperatures in the heating mode, the heat exchangers are unloaded, which yielded higher efficiency. This efficiency enabled the CCHP prototype to reach a COP >4.0 at $47^{\circ} \mathrm{F}\left(8.3^{\circ} \mathrm{C}\right)$.

5. For CCHPs, the compressor(s) should be well insulated and placed outside the outdoor airflow stream to minimize the shell heat loss. Insulating the compressors increases the heat rejection of the condenser (outdoor heat exchanger) in cooling mode, thus reducing the cooling performance. However, this effect is negligible for the CCHP prototype because the condenser is oversized for cooling mode operation with only one compressor.

6. Heating mode discharge pressure control, which used an electronic expansion valve (EXV) coupled with a suction line accumulator, allowed for optimizing the active charge in the prototype system while pursuing optimum discharge pressure target as a function of the ambient temperature and compressor stage over an extensive operation range. This control also mitigated the typical charge imbalance between cooling and heating modes. A standard thermostatic expansion valve (TXV) was used for the cooling mode.

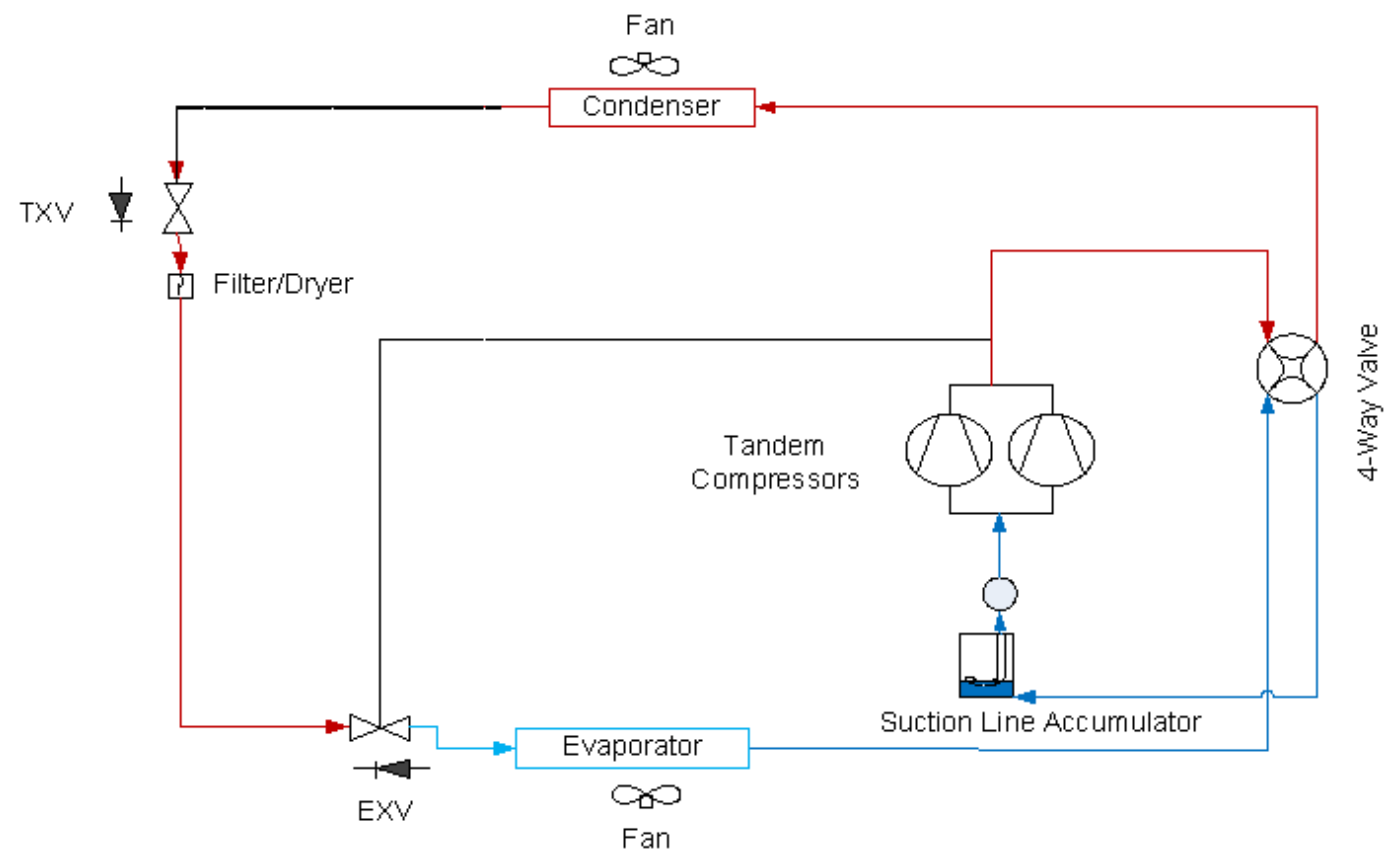

Figure 2. CCHP prototype using tandem, single-speed compressors and an EXV for discharge pressure control in the heating mode. 
The lab prototype using the tandem single-speed compressors reached $4.24 \mathrm{COP}$ at $36,000 \mathrm{Btu} / \mathrm{h}(10.6$ $\mathrm{kW})$ capacity $\left(100 \%\right.$ nominal capacity) and $47^{\circ} \mathrm{F}\left(8.3^{\circ} \mathrm{C}\right) ; 2.9 \mathrm{COP}$ at $110 \%$ nominal capacity and $17^{\circ} \mathrm{F}\left(-8.3^{\circ} \mathrm{C}\right)$; and $1.9 \mathrm{COP}$ at $76 \%$ nominal capacity and $-13^{\circ} \mathrm{F}\left(-25^{\circ} \mathrm{C}\right)$ with an estimated HSPF of 11.2 $\mathrm{Btu} / \mathrm{Wh}$. Using the same tandem compressors in a breadboard heat pump, a field investigation was conducted in an occupied home in Ohio. The field heat pump operated successfully for three years. During the first heating season, the field-measured seasonal heating efficiency was $10.8 \mathrm{Btu} / \mathrm{Wh}$, and the heat pump field prototype operated down to $-13^{\circ} \mathrm{F}\left(-25^{\circ} \mathrm{C}\right)$ and eliminated resistance heat use. The heat pump prototype achieved a $40 \%$ energy reduction compared to the previous heat pump when comparing monthly utility bills with similar average monthly temperatures of $20^{\circ} \mathrm{F}\left(-6.7^{\circ} \mathrm{C}\right)$. The heat pump field prototype maintained an acceptable comfort level during the heating season.

\section{REDESIGN}

Although ORNL's CCHP prototype delivered the performance metrics required by DOE, further improvements were needed to reduce the cost and improve customer satisfaction. Since 2015, OEMs have provided feedback regarding the tandem design: (a) the tandem compressors require too large of a footprint to fit in some residential outdoor units; (b) a single-speed compressor was used for cooling season; however, allowing capacity modulation is still desirable to some degree for a higher seasonal energy efficiency ratio (SEER); (c) because customers may demand higher supply air temperatures than those designed for efficient operation, a "comfort mode" option should be provided to raise the supply air temperature via reducing the indoor airflow rate as needed; and (d) costs could be reduced, for example, by reducing the heat exchanger size per nominal tonnage or using a single multi-stage compressor instead of two parallel compressors.

While keeping the most useful features stated in Section 1.1, the CCHP prototype was redesigned with these modifications:

1. Single three-stage compressor versus tandem compressors-Our industry partner, Emerson Commercial \& Residential Solutions, recently developed an advanced multi-stage scroll compressor product, which provides capacity output at three levels: 50\%, 67\%, and 100\%. This single three-stage compressor will replace the tandem compressors.

2. Capacity modulation strategy - Controls will be developed for the three-stage compressor that allow it to be operated by a typical two-stage thermostat. To allow capacity modulation in the cooling mode and overcapacity at low ambient temperatures in the heating mode, the $67 \%$ capacity output level was selected as the nominal. This selection allows the 50\% capacity output to be used during part load conditions coinciding with moderate ambient temperatures. The $100 \%$ output capacity is used for low-temperature heating operation. To operate the system with a two-stage thermostat, the low-stage (Y1) and high-stage (Y2) outputs of the thermostat were mapped to the three levels of capacity output of the compressor using the measured ambient temperature as a crossover point. A low-stage call for heating or cooling results in operation at the $50 \%$ capacity level at all ambient temperatures. At ambient temperatures at or above $20^{\circ} \mathrm{F}\left(-6.7^{\circ} \mathrm{C}\right)$, a high-stage call for heating or cooling results in operation at the $67 \%$ capacity level. At temperatures below $20^{\circ} \mathrm{F}\left(-6.7^{\circ} \mathrm{C}\right)$, high-stage calls for heating result in operation at the $100 \%$ capacity level.

3. Compressor sizing - A three-stage compressor with a maximum capacity of $51,000 \mathrm{Btu} / \mathrm{h}(14.9 \mathrm{~kW})$ will replace the tandem compressors with a maximum capacity of $62,000 \mathrm{Btu} / \mathrm{h}(18.2 \mathrm{~kW})$. The CCHP with the three-stage compressor operating at $67 \%$ output capacity has a 3.5 -ton nominal capacity. The CCHP with tandem compressors operating at 50\% output capacity has a 3-ton nominal capacity. Total compressor size is reduced with the three-stage compressor, but the heat pump's 
nominal capacity increases. This trade-off can reduce the compressor cost per nominal tonnage by $30 \%$.

4. Heat exchanger sizing - The indoor and outdoor heat exchangers from the previous design will be used for a heat pump with a nominal capacity of 3.5-ton instead of 3-ton, which results in $17 \%$ heat exchanger cost reduction per nominal tonnage.

5. Control of indoor airflow rate between economy and comfort modes: - To accommodate typical duct size relative to the building design load, heat pumps tend to circulate indoor air at a flow rate between 350 and $450 \mathrm{CFM}\left(0.17\right.$ and $\left.0.21 \mathrm{~m}^{3} / \mathrm{s}\right)$ per nominal tonnage. Therefore, a 3.5-ton heat pump typically has an indoor airflow rate up to $1,575 \mathrm{CFM}\left(0.74 \mathrm{~m}^{3} / \mathrm{s}\right)$. For comfort mode, the indoor airflow rate will be decreased to increase the supply air temperature. There are two options for the indoor air blower: (1) a two-speed electronically commutated motor (ECM) blower (running a low airflow rate of 1,200 CFM $\left(0.57 \mathrm{~m}^{3} / \mathrm{s}\right)$ for increased comfort), which has a fan efficiency around $30 \%$; and (2) a full variable-speed blower with backward-curved impeller made by Ebm-papst. The Ebm-papst blower can precisely control the supply air temperature, and it has a higher fan efficiency around $50 \%$.

6. Customized options for efficiency and product cost: Better efficiency typically comes with higher cost; for example, using an EXV for head pressure control is more efficient but also more expensive than using a TXV to control the suction superheat degree, and an Ebm-papst blower is more efficient but also more expensive than a common ECM blower. Based on the basic features of a three-stage scroll compressor and heat exchangers, customers can customize the expansion device and the indoor blower.

\section{MODELING AND SIMULATION}

Based on the preliminary three-stage compressor performance data from the manufacturer, the DOE/ORNL heat pump design model (Oak Ridge National Laboratory n.d.) was used to design and model the improved CCHP. The simulated heating performance results for three design scenarios are given in Table 1: (1) use a TXV for throttling and a two-speed ECM blower in the heating mode; (2) use an EXV for head pressure control and a two-speed ECM blower; and (3) use an EXV for head pressure control and an Ebm-papst backward-curved blower for increased efficiency. The predicted performance results are given respectively responding to the high-stage (Y2) and low-stage (Y1) calls of a two-stage thermostat. To calculate the HSPF of a two-stage heat pump, performance results at $47^{\circ} \mathrm{F}\left(8.3^{\circ} \mathrm{C}\right), 35^{\circ} \mathrm{F}$ $\left(1.7^{\circ} \mathrm{C}\right)$, and $17^{\circ} \mathrm{F}\left(-8.3^{\circ} \mathrm{C}\right)$ ambient and two capacity levels are required by AHRI 210/240 (AHRI 2008). For all conditions in Table 1, the indoor airflow rate was set at 1,500 CFM $\left(0.71 \mathrm{~m}^{3} / \mathrm{s}\right)$ with $0.2 \mathrm{in}$. water column (5.0 Pa) external static pressure. The outdoor fan uses an ECM motor that delivers 3,350 CFM $\left(1.58 \mathrm{~m}^{3} / \mathrm{s}\right)$ airflow rate with $300 \mathrm{~W}$ power. The EXV will not only facilitate optimum head pressure control but also accelerate the heat pump start-up by totally shutting off the refrigerant flow at the end of cycles to prevent the system pressures from equalizing, unlike a TXV. Therefore, it was assumed that the heating cyclic degradation coefficient $\left(C_{D}^{h}\right)$ of the EXV system was 0.1 compared with a typical $C_{D}^{h}$ value of 0.15 for systems that use a TXV. The standard procedure [1] was followed to calculate the HSPFs for the three scenarios. The combination of a TXV and ECM blower yields an HSPF (in region IV) of 11.1 $\mathrm{Btu} / \mathrm{Wh}$; the EXV and ECM blower combination yields an HSPF of $11.6 \mathrm{Btu} / \mathrm{Wh}$; and use of the EXV and Ebm-papst blower yields an HSPF of 12.0 Btu/Wh. 
Table 1. Predicted heating performance of the improved CCHP.

\begin{tabular}{|c|c|c|c|c|c|c|c|c|}
\hline & Stage & $\begin{array}{c}\text { Ambient } \\
\text { temp. }\left({ }^{\circ} \mathbf{C}\right)\end{array}$ & $\begin{array}{c}\text { Capacity } \\
(\mathbf{k W})\end{array}$ & $\begin{array}{c}\text { COP } \\
(W / W)\end{array}$ & $\begin{array}{l}\text { Compressor } \\
\text { capacity }(\%)\end{array}$ & $\begin{array}{l}\text { Compressor } \\
\text { power }(W)\end{array}$ & $\begin{array}{c}\text { Blower } \\
\text { power } \\
(W)\end{array}$ & $\begin{array}{c}\text { Supply } \\
\text { temp. } \\
\left({ }^{\circ} \mathrm{C}\right)\end{array}$ \\
\hline \multirow{7}{*}{$\begin{array}{c}\text { TXV+ECM } \\
\text { blower; } \\
\text { assume } C_{D}^{h}= \\
0.15 ; \mathbf{H S P F}= \\
\mathbf{1 1 . 1} \text { Btu/Wh }\end{array}$} & \multirow{3}{*}{$\begin{array}{l}\text { High } \\
(\mathrm{Y} 2)\end{array}$} & 8.3 & 12.6 & 3.93 & 67 & 2,663 & 235 & 36.5 \\
\hline & & 1.7 & 10.6 & 3.41 & 67 & 2,564 & 235 & 33.9 \\
\hline & & -8.3 & 11.0 & 2.91 & 100 & 3,239 & 235 & 34.5 \\
\hline & \multirow{4}{*}{$\begin{array}{l}\text { Low } \\
(\mathrm{Y} 1)\end{array}$} & 16.7 & 12.2 & 5.05 & 50 & 1,876 & 235 & 36.1 \\
\hline & & 8.3 & 9.9 & 4.20 & 50 & 1,814 & 235 & 33.1 \\
\hline & & 1.7 & 8.2 & 3.53 & 50 & 1,778 & 235 & 30.9 \\
\hline & & -8.3 & 6.0 & 2.62 & 50 & 1,736 & 235 & 28.2 \\
\hline \multirow{7}{*}{$\begin{array}{c}\mathrm{EXV}+\mathrm{ECM} \\
\text { blower; } \\
\text { assume } C_{D}^{h}= \\
0.1 ; \mathbf{H S P F}= \\
\mathbf{1 1 . 6} \mathrm{Btu} / \mathbf{W h}\end{array}$} & \multirow{3}{*}{$\begin{array}{l}\text { High } \\
(\mathrm{Y} 2)\end{array}$} & 8.3 & 12.6 & 3.93 & 67 & 2,680 & 235 & 36.6 \\
\hline & & 1.7 & 10.7 & 3.43 & 67 & 2,582 & 235 & 34.2 \\
\hline & & -8.3 & 11.1 & 2.92 & 100 & 3,271 & 235 & 34.7 \\
\hline & \multirow{4}{*}{$\begin{array}{l}\text { Low } \\
(\mathrm{Y} 1)\end{array}$} & 16.7 & 12.2 & 5.04 & 50 & 1,887 & 235 & 36.1 \\
\hline & & 8.3 & 10.0 & 4.25 & 50 & 1,826 & 235 & 33.3 \\
\hline & & 1.7 & 8.5 & 3.65 & 50 & 1,791 & 235 & 31.3 \\
\hline & & -8.3 & 6.4 & 2.81 & 50 & 1,749 & 235 & 28.8 \\
\hline \multirow{7}{*}{$\begin{array}{c}\text { EXV+Ebm- } \\
\text { papst blower; } \\
\text { assume } C_{D}^{h}= \\
0.1 ; \mathbf{H S P F}= \\
\mathbf{1 2 . 0} \mathrm{Btu} / \mathbf{W h}\end{array}$} & \multirow{3}{*}{$\begin{array}{l}\text { High } \\
(\mathrm{Y} 2)\end{array}$} & 8.3 & 12.5 & 4.00 & 67 & 2,680 & 141 & 36.4 \\
\hline & & 1.7 & 10.6 & 3.51 & 67 & 2,582 & 141 & 34.0 \\
\hline & & -8.3 & 11.0 & 2.97 & 100 & 3,271 & 141 & 34.6 \\
\hline & \multirow{4}{*}{$\begin{array}{l}\text { Low } \\
(\mathrm{Y} 1)\end{array}$} & 16.7 & 12.1 & 5.21 & 50 & 1,887 & 141 & 35.9 \\
\hline & & 8.3 & 10.0 & 4.39 & 50 & 1,826 & 141 & 33.2 \\
\hline & & 1.7 & 8.4 & 3.76 & 50 & 1,791 & 141 & 31.2 \\
\hline & & -8.3 & 6.3 & 2.88 & 50 & 1,749 & 141 & 28.7 \\
\hline
\end{tabular}

Table 2 presents predicted performance indices at the required conditions to calculate the SEER for a twostage air conditioner. The results are given respectively responding to the low-stage (Y1) and high-stage (Y2) calls of a two-stage thermostat. At the high stage, 67\% compressor volume and 1,500 CFM (0.71 $\left.\mathrm{m}^{3} / \mathrm{s}\right)$ indoor airflow rate were used. At the low stage, 50\% compressor volume and 1,200 CFM (0.57 $\mathrm{m}^{3} / \mathrm{s}$ ) indoor airflow rate were used. A TXV was used for the cooling mode, and a cooling degradation coefficient $\left(C_{D}^{c}\right)$ of 0.1 was assumed. The resultant SEER using the two-speed ECM blower is 15.6 $\mathrm{Btu} / \mathrm{Wh}$, and the SEER using the Ebm-papst blower is $16.2 \mathrm{Btu} / \mathrm{Wh}$. 
Table 2. Predicted cooling performance of the improved CCHP.

\begin{tabular}{|c|c|c|c|c|c|c|c|c|}
\hline & Stage & $\begin{array}{l}\text { Ambient } \\
\text { temp. }\left({ }^{\circ} \mathbf{C}\right)\end{array}$ & $\begin{array}{c}\text { Capacity } \\
(\mathbf{k W})\end{array}$ & $\begin{array}{c}\text { EER } \\
(\text { Btu/Wh })\end{array}$ & $\begin{array}{l}\text { Compressor } \\
\text { capacity }(\%)\end{array}$ & $\begin{array}{c}\text { Compressor } \\
\text { power }(W)\end{array}$ & $\begin{array}{c}\text { Blower } \\
\text { power } \\
\text { (W) }\end{array}$ & $\begin{array}{c}\text { Sensible } \\
\text { heat ratio } \\
(\%)\end{array}$ \\
\hline \multirow{4}{*}{$\begin{array}{c}\text { TXV+ECM } \\
\text { blower; } \\
\text { SEER = } \\
\text { 15.6 Btu/Wh }\end{array}$} & \multirow{2}{*}{$\begin{array}{l}\text { High } \\
\text { (Y2) }\end{array}$} & 35.0 & 12.6 & 12.46 & 67 & 2,926 & 235 & 77 \\
\hline & & 27.8 & 13.6 & 15.60 & 67 & 2,433 & 235 & 75 \\
\hline & \multirow{2}{*}{$\begin{array}{l}\text { Low } \\
\text { (Y1) }\end{array}$} & 35.0 & 9.8 & 13.09 & 50 & 2,074 & 180 & 78 \\
\hline & & 27.8 & 10.5 & 16.36 & 50 & 1,712 & 180 & 76 \\
\hline \multirow{4}{*}{$\begin{array}{c}\text { TXV+Ebm- } \\
\text { papst blower; } \\
\text { SEER = } \\
\text { 16.2 Btu/Wh }\end{array}$} & \multirow{2}{*}{$\begin{array}{l}\text { High } \\
\text { (Y2) }\end{array}$} & 35.0 & 12.7 & 12.90 & 67 & 2,926 & 141 & 77 \\
\hline & & 27.8 & 13.7 & 16.23 & 67 & 2,431 & 141 & 75 \\
\hline & \multirow{2}{*}{$\begin{array}{l}\text { Low } \\
\text { (Y1) }\end{array}$} & 35.0 & 9.9 & 13.58 & 50 & 2,073 & 108 & 77 \\
\hline & & 27.8 & 10.6 & 17.04 & 50 & 1,711 & 108 & 75 \\
\hline
\end{tabular}

\section{LABORATORY TESTS}

Based on the modeling results from Section 3, a prototype CCHP system was designed and built for laboratory testing in 2020. The prototype was built from a 4.5-ton two-stage heat pump rated at 54,500 $\mathrm{Btu} / \mathrm{h}(16.0 \mathrm{~kW})$ cooling capacity, 16.0 Btu/Wh SEER, 55,000 Btu/h $(16.1 \mathrm{~kW})$ heating capacity, and 8.5 $\mathrm{Btu} / \mathrm{Wh}$ HSPF. The original compressor and expansion device in the outdoor unit were removed. The compressor was replaced with a prototype three-stage, $51,000 \mathrm{Btu} / \mathrm{h}(14.9 \mathrm{~kW})$ compressor that was provided by Emerson Commercial \& Residential Solutions. Three stages are achieved by using a twostage scroll compressor in combination with a speed controller, as depicted in Figure 3. The original modeling in Section 3 used capacities of 100\%, 67\%, and 50\%, however the compressor used in prototype provided capacities of $100 \%, 67 \%$, and $45 \%$ of full capacity. An EXV and controller were also installed to serve as the expansion device in the heating mode. For ease of installation, the new compressor with controls was installed next to the outdoor unit on a wooden pallet in the outdoor environmental chamber. Photographs of the equipment setup in both chambers are shown in Figure 4 and Figure 5. Cooling and heating capacities were calculated using the indoor air enthalpy method and the refrigerant enthalpy method as described in ASHRAE Standard 37 (ASHRAE 2009). 


\section{Low stage}
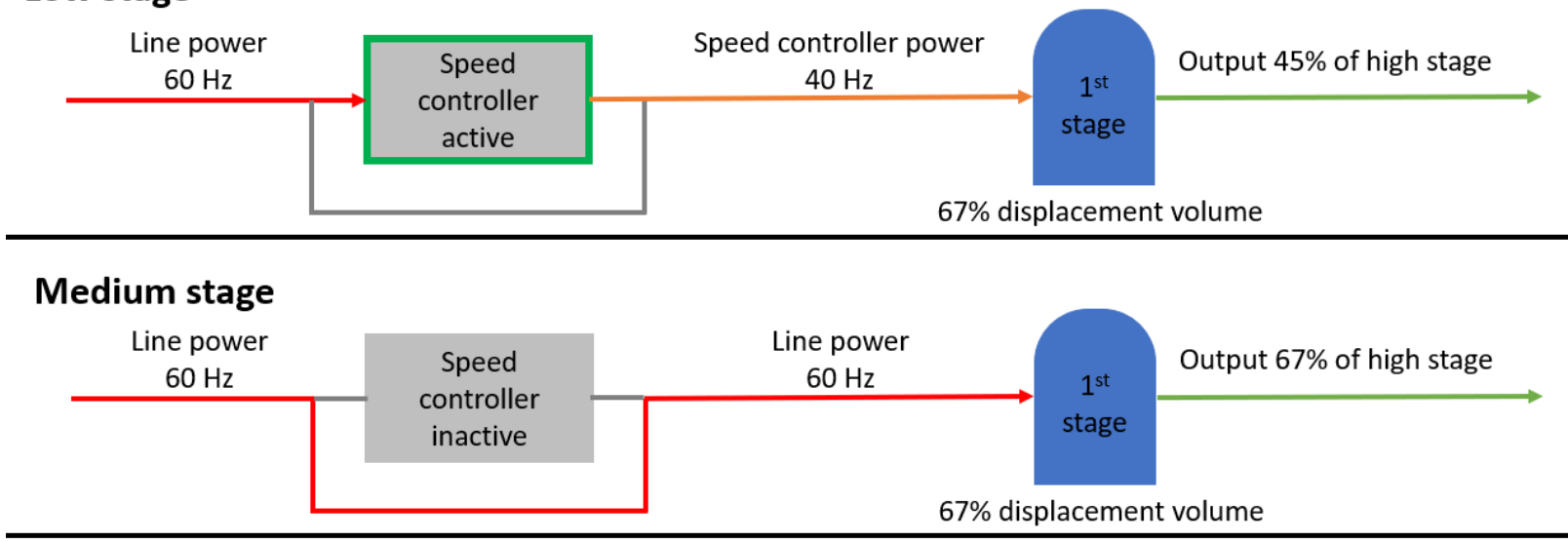

\section{High stage}

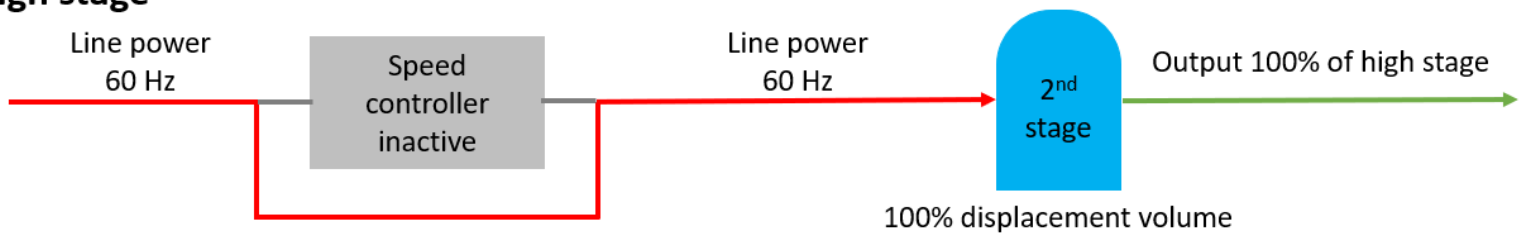

Figure 3. Diagram of speed controller and two-stage heat pump configuration used to achieve three stages of operation.

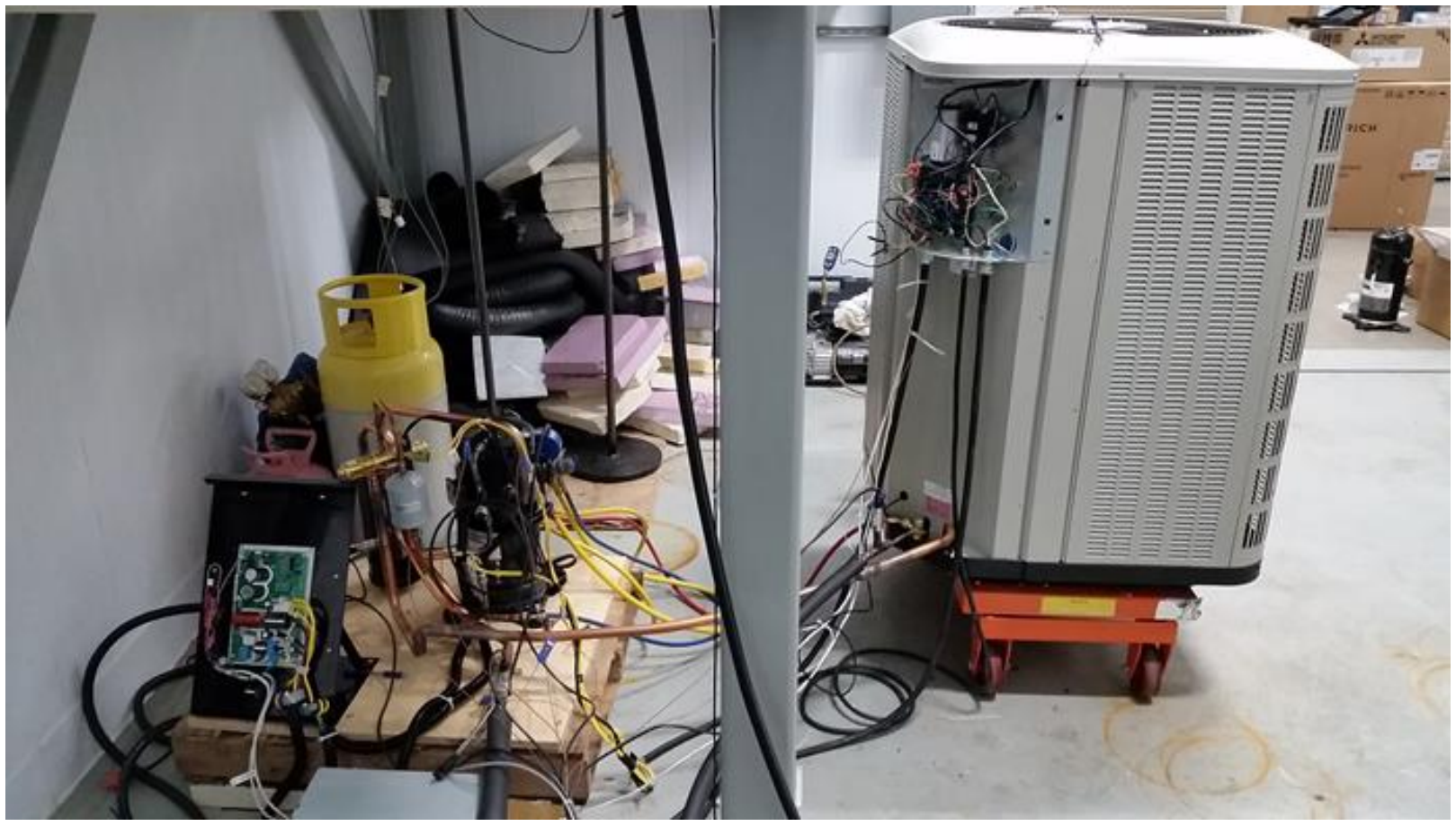

Figure 4. Compressor, speed controller, reversing valve, and accumulator on a pallet next to the outdoor unit heat exchanger as installed in the outdoor environmental chamber. 


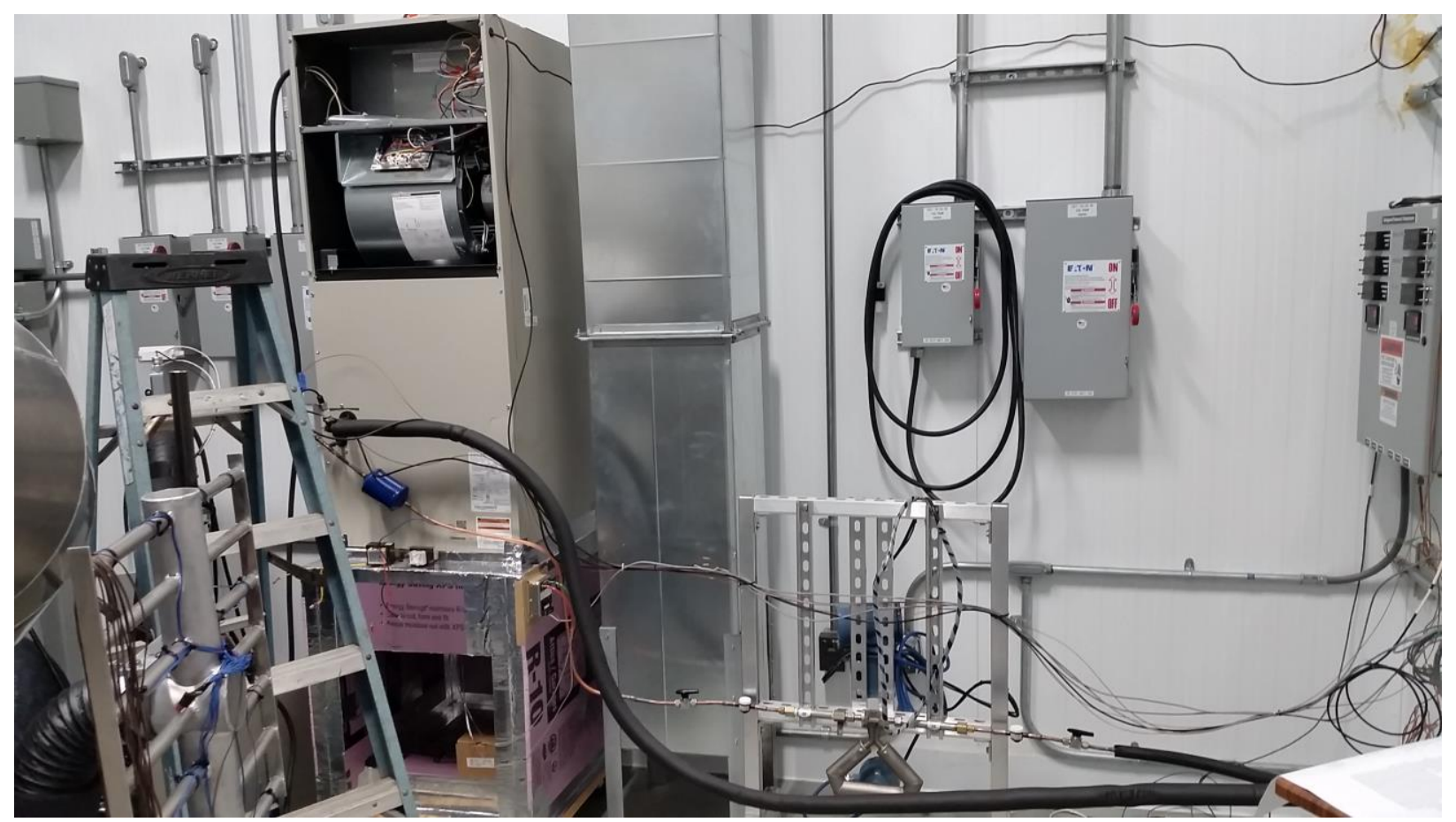

Figure 5. Indoor unit installed in the indoor environmental chamber.

Tests were run at conditions specified for ratings tests of the unit. The compressor stage, outdoor fan speed (low, medium, or high), indoor fan speed (low or high), and outdoor expansion valve opening were controlled manually for the laboratory testing. Capacity results from the laboratory tests and performance targets for the system are shown in Figure 6. If the system were rated with 3.5 tons of nominal cooling capacity (having two stages of cooling and three stages of heating) the performance of the system would not meet the original capacity performance targets. These are ambitious low-temperature capacity targets, which are difficult to meet at a low cost. However, in very cold climates, where additional lowtemperature capacity is required, the prototype system could be oversized, or rated as a 2.5-ton system, with a single stage of cooling and three stages of heating. The system would easily surpass the capacity targets in this scenario, albeit at a higher cost per nominal ton of cooling. The COP results of the laboratory testing are plotted in Figure 7 . The system met the efficiency targets at both $-10^{\circ} \mathrm{F}\left(-23^{\circ} \mathrm{C}\right)$ and $17^{\circ} \mathrm{F}\left(-8.3^{\circ} \mathrm{C}\right)$ ambient temperatures. 


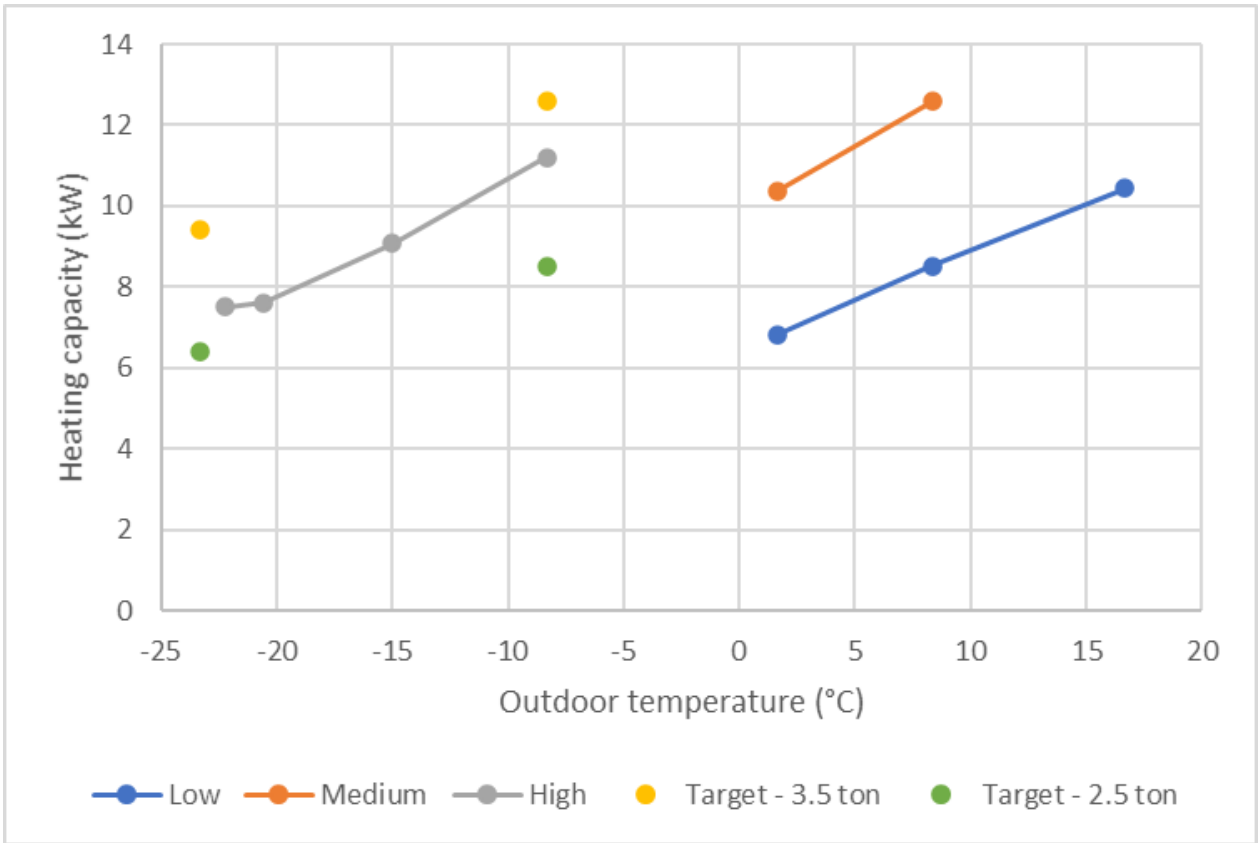

Figure 6. Laboratory-measured capacity of the prototype system along with performance targets if the system were rated as a 3.5-ton nominal cooling unit and 2.5-ton nominal cooling unit.

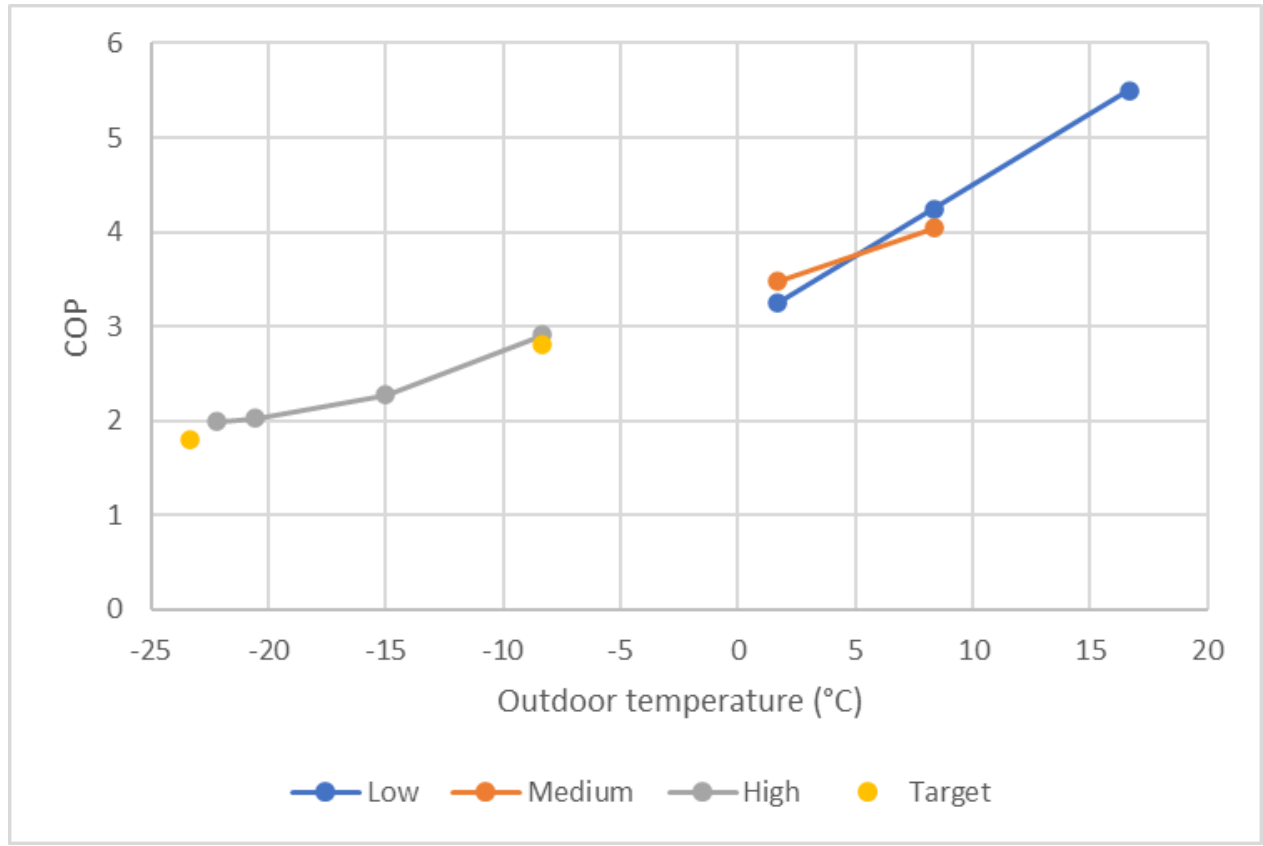

Figure 7. Laboratory-measured efficiency of the prototype system along with efficiency targets.

The laboratory test data were used to estimate the seasonal performance in terms of SEER for cooling performance and HSPF for heating. The heating performance was also evaluated using the HSPF2 metric for heating, because it will replace the HSPF metric in 2023. Estimates of the SEER, HSPF according to the DOE test procedure Appendix M heating load lines (10 CFR Part 430 2021), and HSPF2 according to the DOE test procedure Appendix M1 heating load lines (10 CFR Part 430 2021) are shown in Table 3. The triple-capacity northern heat pump rating procedure was followed for calculating the SEER, HSPF, and HSPF2 values for the 3.5-ton nominal cooling case. For the 2.5-ton nominal cooling case, a single- 
stage cooling bin method calculation was used for estimating the SEER, and the triple-capacity northern heat pump rating procedures were used for the HSPF and HSPF2 calculations. The values presented in Table 3 are only estimates because the test procedures for ratings were not strictly followed. One notable deviation was that the external static pressure of the indoor unit was not controlled specifically according to either Appendix M or Appendix M1 values. The only differences between the HSPF and HSPF2 values were the building heating load lines and associated modifications to the outdoor ambient bin hours owing to different zero heating load ambient temperatures. Rating the system with one stage of cooling instead of two reduced the estimated SEER by approximately $4 \%$. This reduction is due to additional cyclic losses that offset any gains from only operating at the lowest compressor capacity. The estimated HSPF for both Region IV and Region V decreased, as well. However, the HSPF2 values, with updated building heating loads, for Region IV and Region V increased by $1 \%$ and $10 \%$, respectively, illustrating the benefits of having higher heating capacity available in very cold climates like those in Region $\mathrm{V}$.

Table 3. Estimated seasonal efficiencies based on laboratory test data.

\begin{tabular}{|l|c|c|}
\hline & $\begin{array}{c}\text { 3.5-ton nominal cooling } \\
\text { two-stage cooling } \\
\text { three-stage heating }\end{array}$ & $\begin{array}{c}\text { 2.5-ton nominal cooling } \\
\text { one-stage cooling } \\
\text { three-stage heating }\end{array}$ \\
\hline SEER $(\mathrm{Btu} / \mathrm{Wh})$ & 17.15 & 16.38 \\
\hline HSPF Region IV $(\mathrm{Btu} / \mathrm{Wh})$ & 10.97 & 10.54 \\
\hline HSPF Region V $(\mathrm{Btu} / \mathrm{Wh})$ & 9.47 & 8.96 \\
\hline HSPF2 Region IV $(\mathrm{Btu} / \mathrm{Wh})$ & 10.15 & 10.29 \\
\hline HSPF2 Region V $(\mathrm{Btu} / \mathrm{Wh})$ & 8.19 & 9.03 \\
\hline
\end{tabular}

\section{FIELD TEST}

After conclusion of the laboratory testing, the construction of a field test prototype began. The major task associated with converting the laboratory test prototype to a field test prototype was developing the controls required to allow the system to operate automatically in response to a conventional two-stage thermostat without human intervention. Control algorithms were developed for the heating startup routine, controlling the opening of the EXV in the heating mode, and for the staging of the compressor and fans based on ambient temperature and the demand from the thermostat (i.e., low or high stage). These controls were layered on top of the existing controls in the outdoor unit. Therefore, the outdoor unit control board determined when to initiate and terminate defrost cycles, and the factory safeties for high and low pressure also remained functional. The controls were integrated with the data logger that was used for performance measurement and monitoring.

For ease of construction and servicing, the compressor, accumulator, reversing valve, data logger, most of the instrumentation, and controls for the outdoor unit were installed in a wooden crate, as shown in Figure 8 . 


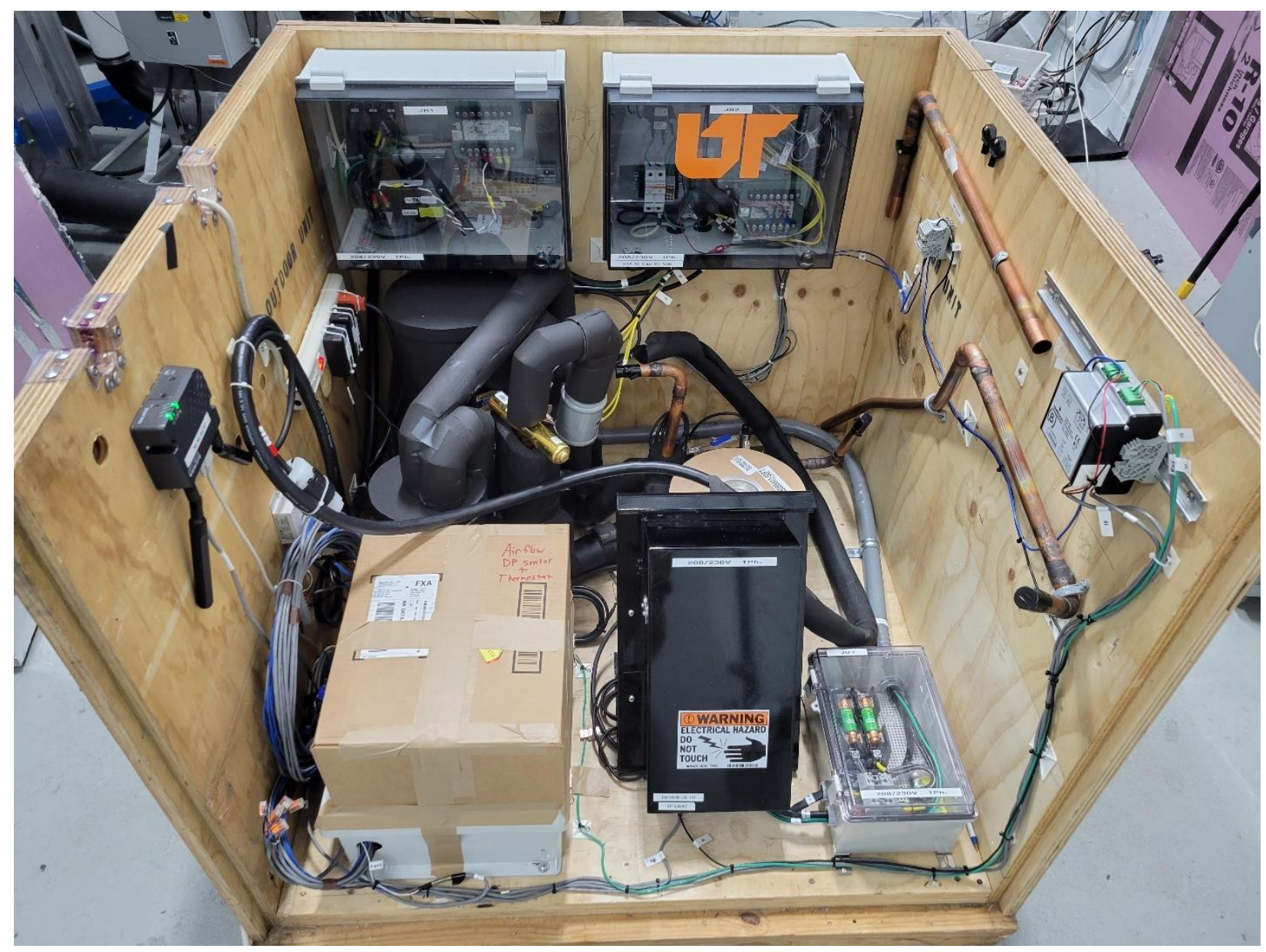

Figure 8. Compressor crate prior to shipment to the field test site.

The system was paired with a conventional two-stage thermostat. Figure 9 shows how the low-stage and high-stage thermostat calls were mapped to the three compressor stages for heating and cooling. At temperatures above $35^{\circ} \mathrm{F}\left(1.7^{\circ} \mathrm{C}\right)$, the low- and high-stage calls for conditioning were mapped to the low and medium compressor stages, respectively. Between $20^{\circ} \mathrm{F}\left(-6.7^{\circ} \mathrm{C}\right)$ and $35^{\circ} \mathrm{F}\left(1.7^{\circ} \mathrm{C}\right)$, a low-stage heat call was mapped to the medium compressor stage, and a high-stage call was mapped to the high compressor stage. Below $20^{\circ} \mathrm{F}\left(-6.7^{\circ} \mathrm{C}\right)$, any call for heat resulted in high-stage compressor operation. A $5^{\circ} \mathrm{F}$ deadband $\left(2.7^{\circ} \mathrm{C}\right.$ deadband $)$ centered on the transition points was used to prevent the system from rapidly changing stages back and forth when the outdoor temperature was at the transition point temperatures. 


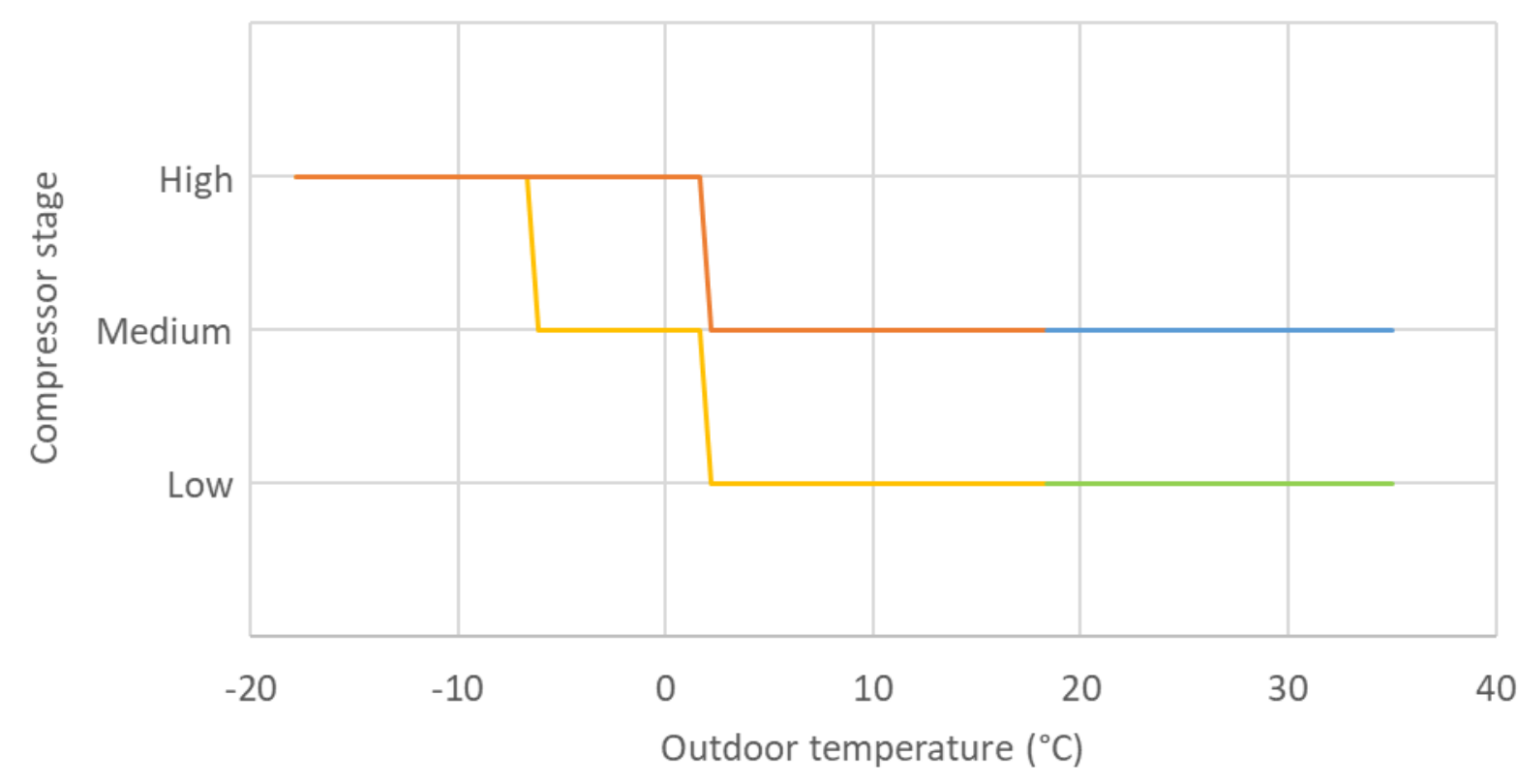

Thermostat output

— Low stage heat — High stage heat — Low stage cool — High stage cool

Figure 9. Mapping of two-stage thermostat calls for heating and cooling to compressor staging.

The compressor discharge pressure was used as the control input for the heating EXV control. Laboratory test data and modeling yielded a map of the optimal pressure for each stage and outdoor temperature. A preliminary mapping of the current signal input to the expansion valve controller was used during startup and to set upper and lower limits on the opening of the expansion valve. After the startup routine, a proportional-integral-derivative controller was used to maintain the target pressure.

The system arrived at the field test site in Fairbanks, Alaska in mid-March 2021. It was installed and commissioned the last week in March 2021, and data collection began immediately. The field test will continue through the winter of 2021/2022, but preliminary results are provided in this report.

The air-side capacity of the system was calculated using measurements of the airflow rate and the return and supply air temperatures. Supply and return air temperatures were measured with grids of thermocouples located at the supply and return of the fan-coil unit. A Pitot array airflow station that was calibrated using a code tester meeting the requirements specified in ASHRAE Standard 37 (ASHRAE 2009) was used to measure the airflow rate. The average capacity for each hour that had more than 5 min of runtime in each stage is plotted in Figure 10. For reference, the laboratory-measured capacity is also plotted with the field-measured data. The low- and medium-stage capacities match very well with the laboratory test data. The low-stage data from the field shows a slightly lower capacity than the laboratory data at higher ambient temperatures. This difference could be a result of limited runtime at these conditions and the system being unable to achieve steady-state operation. Similarly, the average COP for each stage is plotted in Figure 11 along with the laboratory-measured COP. The field-test data generally agree well with the laboratory-test data. The field-measured low-stage COP is lower than the laboratorymeasured COP, which is likely a result of running the indoor blower at high speed, consuming additional power compared with the laboratory test when it was run at a low stage. This setting was a simplification for the controls in the field test, but it will be investigated next winter to discover whether improvement is 
possible. The medium-stage COP measurement from the field matches very well with the laboratory test data. The high-stage data shows slightly better COPs than the laboratory data. This improvement is likely a result of the lower return air temperatures reducing the compressor power during high compression ratio conditions that exist at very low outdoor temperature conditions. The small drop in COP between $0^{\circ} \mathrm{F}$ $\left(-18^{\circ} \mathrm{C}\right)$ and $5^{\circ} \mathrm{F}\left(-15^{\circ} \mathrm{C}\right)$ is caused by the transition from high indoor blower speed to low indoor blower speed. The lower blower speed decreases the efficiency but provides higher supply air temperatures that are more comfortable to occupants. The $5^{\circ} \mathrm{F}\left(-15^{\circ} \mathrm{C}\right)$ laboratory test data was run with the indoor blower on the low setting, which also contributes to some of the difference in COP between the field and laboratory data.

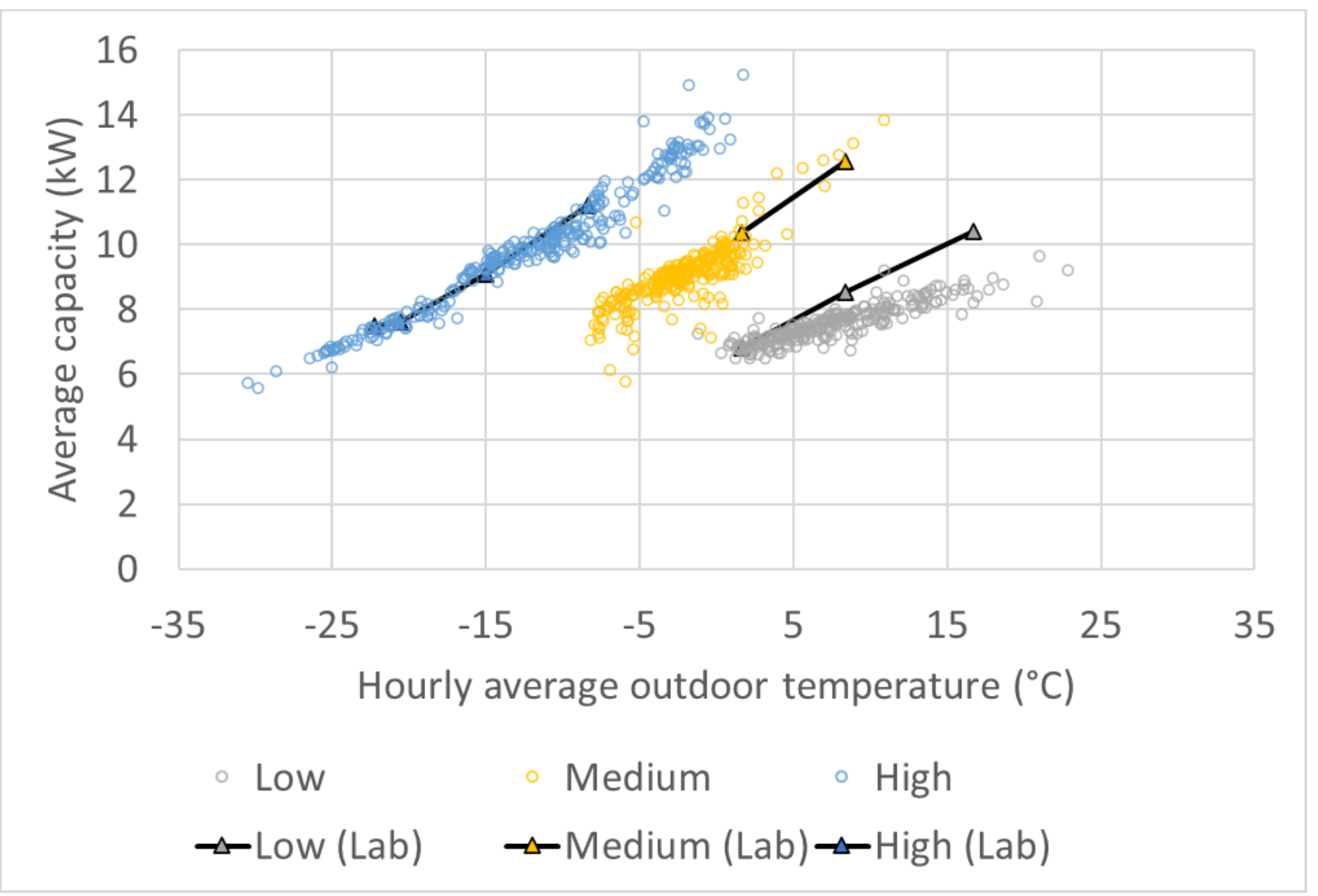

Figure 10. Average measured capacity of the field-test unit for hours with more than 5 min of runtime in the indicated stage compared with the measured laboratory data. 


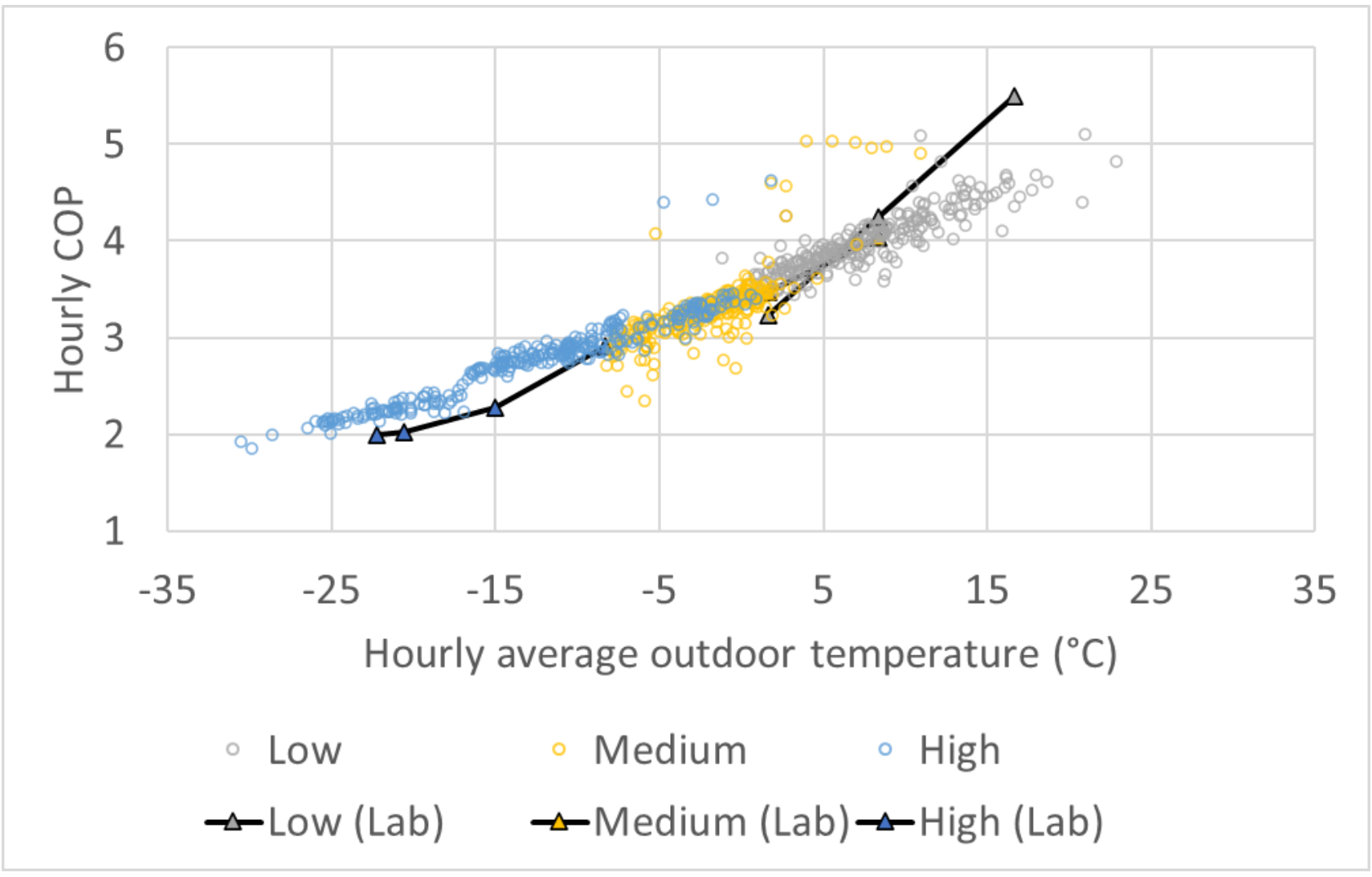

Figure 11. Average measured COP of the field-test unit for hours with more than 5 min of runtime in the indicated stage compared with the measured laboratory data.

One concern identified during testing was the frequency of defrost cycles at low-temperature ambient conditions. A plot of the percentage of runtime that the unit operated in the defrost mode is shown in Figure 12. At temperatures below $10^{\circ} \mathrm{F}\left(-12^{\circ} \mathrm{C}\right)$, the system was still defrosting every couple of hours. Two potential solutions for this issue were identified and implemented by staff at the field test site. The first solution was to cut a large hole in the center of the outdoor unit base pan during the installation of the system to promote drainage of water from defrost cycles. This solution had the unintended effect of allowing a portion of the outdoor unit airflow to bypass the coil. Effectively reducing the airflow caused the coil to operate at lower temperatures than typically required and can cause the system to defrost more frequently because the defrost control logic is based on the temperature difference between the outdoor coil and ambient air. The second solution was to relocate the ambient air temperature sensor from inside the control box of the outdoor unit to a shaded area on the exterior of the unit to ensure that the sensor accurately measured the ambient temperature. 


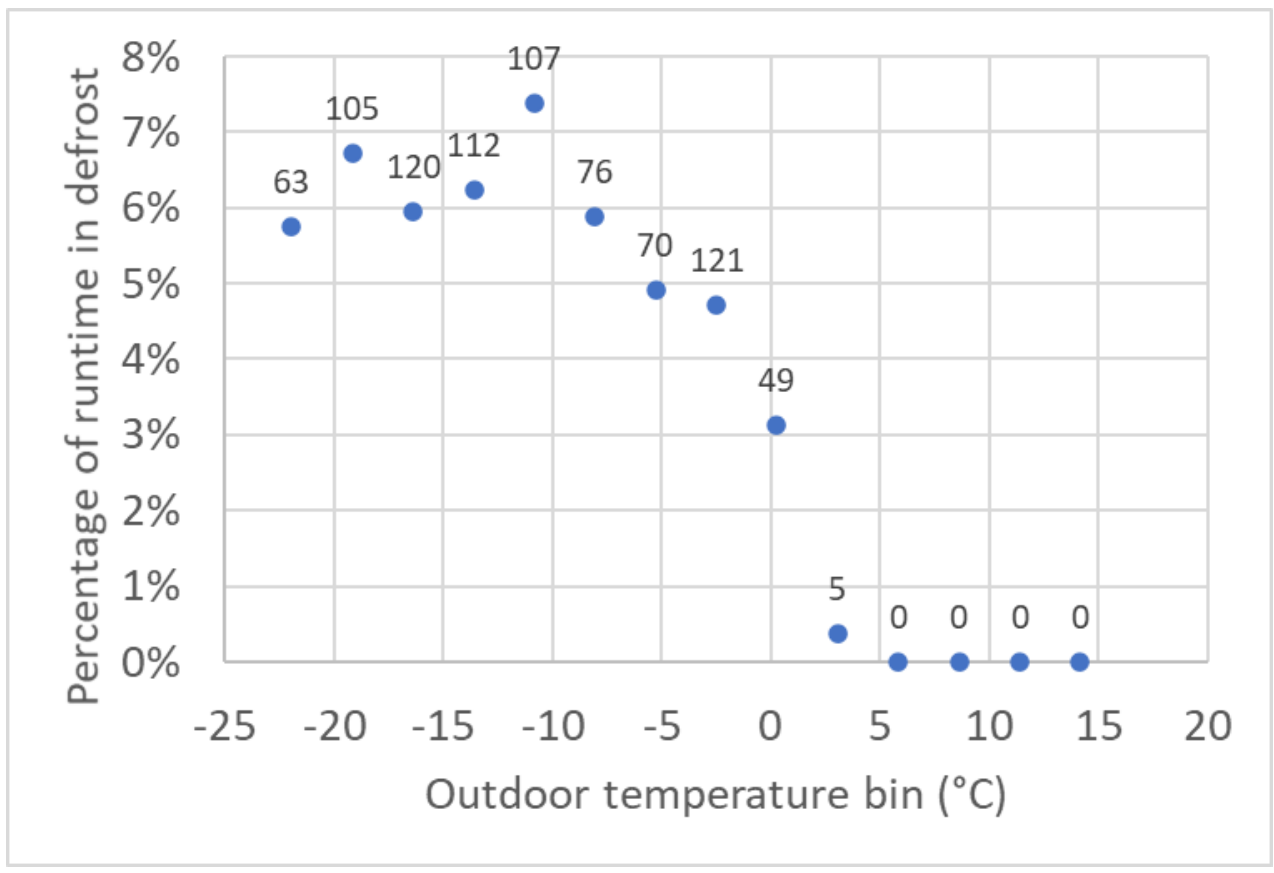

Figure 12. Plot of the percentage of runtime in defrost mode for $5^{\circ} \mathrm{F}$ outdoor temperature bins $\left(2.7^{\circ} \mathrm{C}\right.$ bins $)$ with labels showing minutes of runtime in defrost mode.

\section{CONCLUSION}

This report describes the design process for a low-cost CCHP. The design was initially evaluated via modeling and simulation, followed by laboratory tests and a field test on prototype systems. The system was designed around a prototype three-stage compressor that offers an additional stage of capacity flexibility relative to a two-stage compressor while avoiding the high cost of variable-speed heat pumps. If rated as a typical triple-capacity, cold-climate heat pump, the system would achieve an estimated 17.15 Btu/Wh SEER, 10.97 Btu/Wh Region IV HSPF, and 9.47 Btu/Wh Region V HSPF. Based on Appendix M1 heating load lines, effective January 1, 2023, the system achieves an estimated 10.15 Btu/Wh Region IV HSPF2 and $8.19 \mathrm{Btu} / \mathrm{Wh}$ Region V HSPF2. In cold climates like Region V, oversizing the unit by sizing the lowest stage to meet the required cooling capacity may be appropriate. This results in a singlestage cooling system that retains three stages for heating. The prototype system would therefore be derated by 1 ton of nominal cooling capacity and achieve an estimated 16.38 Btu/Wh SEER and 9.03 Btu/Wh Region V HSPF2 (more than a 10\% increase in HSPF2 over the system sized for two stages of cooling). Although we have collected limited data from the field test, initial results are quite promising and generally match the laboratory test data. Modifications that should increase performance have been identified and implemented.

\section{REFERENCES}

10 CFR Part 430. 2021. "Appendix M to Subpart B of Part 430 - Uniform Test Method for Measuring the Energy Consumption of Central Air Conditioners and Heat Pumps."

—. 2021. "Appendix M1 to Subpart B of Part 430 - Uniform Test Method for Measuring the Energy Consumption of Central Air Conditioners and Heat Pumps."

AHRI. 2008. 2008 Standard for Performance Rating of Unitary Air-Conditioning \& Air-Source Heat Pump Equipment. Arlington, Virginia: Air-Conditioning, Heating, and Refrigeration Institute. 
ASHRAE. 2009. Standard 37: Methods of Testing for Rating Electrically Driven Unitary AirConditioning and Heat Pump Equipment. Atlanta, GA: American Society of Heating, Refrigerating and Air-Conditioning Engineers, Inc.

Oak Ridge National Laboratory. n.d. Heat Pump Design Model. US Department of Energy. https://hpdmflex.ornl.gov. 

